\title{
ABBREVIATIONS OF CLASSICAL WORKS
}

Ann.

Ant.

Anton.

Aug.

Cels.

Claud.

Conj. praec.

Contempl. Life

Dom.

Eccl. Hist.

Ep.

Epigr.

Fact. et dict.
Eleg.

Tacitus Annales (Annals)

Josephus Antiquitates judaicae (Jewish Antiquities)

Plutarch Antonius (Life of Anthony)

Suetonius Divus Augustus (The Deified Augustus)

Origen Contra Celsum (Against Celsus)

Suetonius Divus Claudius (The Deified Claudius)

Plutarch Conjugalia Praecepta (Advice to Bride and Groom)

Philo De vita contemplativa (On the Contemplative Life)

Suetonius Domitianus (Domitian)

Eusebius Historia ecclesiastica (Ecclesiastical History)

Propertius Elegeiae (Elegies)

Pliny the Younger Epistulae (Letters)

Martial Epigrammata (Epigrams)

Valerius Maximus Factorum et dictorum memorabilium libri novem (Memorable Deeds and Sayings)

Hist. Historiae (author will be indicated in textual citation) 
J.W.

Leg.

Quaest. conv.

Sat.

Spec. Laws

Tib.

Tit.

Vesp.
Josephus Bellum judaicum (Jewish War)

Cicero De legibus (On the Laws)

Plutarch Quaestionum convivialum libri IX (Table Talk)

Juvenal Satirae (Satires)

Philo De specialibus legibus (On the Special Laws) Suetonius Tiberius

Suetonius Divus Titus (The Deified Titus)

Suetonius Vespasianus (Vespasian) 
FIRST CONVERTS 
